\title{
Disciplina Pedagogia Paulo Freire
}

SOUSA, Polliane de ${ }^{1}$

A resenha crítica constitui um tipo de publicação acadêmica que tem por finalidade apresentar uma síntese das ideias fundamentais de uma obra juntamente com considerações sobre alguns dos seus aspectos positivos e negativos (MARCONI; LAKATOS, 2003). No presente texto, o formato textual da resenha crítica é explorado com a finalidade de apresentar uma síntese analítica da disciplina Pedagogia Paulo Freire, desenvolvida pela Cátedra Paulo Freire da Universidade Federal de Pernambuco (UFPE), tendo como referência as vivências da autora no âmbito do Estágio de Docência desenvolvido nesse contexto.

Para compreender a proposta da disciplina Pedagogia Paulo Freire é necessário, inicialmente, situar o seu desenvolvimento no âmbito da Cátedra Paulo Freire/UFPE ${ }^{2}$. Criada pela Portaria ํㅡ 04/2005 do Conselho Universitário da UFPE, a Cátedra constitui espaço de produção e socialização do conhecimento tendo como alicerce o pensamento freireano. Representa, portanto, o reconhecimento institucional e a preservação da memória e do espaço de produção da pedagogia Paulo Freire, desenvolvendo atividades de pesquisa, ensino e extensão (CÁTEDRA PAULO FREIRE/UFPE, 2017).

Como parte das atividades desenvolvidas pela Cátedra Paulo Freire/UFPE, encontra-se a oferta da disciplina institucional Pedagogia Paulo Freire, vinculada ao Departamento de Administração Escolar e Planejamento Educacional do Centro de Educação, oferecida para estudantes regularmente matriculados em cursos de graduação da UFPE e de outras instituições de ensino superior, bem como para portadores de diplomas (CÁTEDRA PAULO FREIRE/UFPE, 2017). A disciplina tem como foco a discussão dos fundamentos da concepção freireana de educação considerando os contextos de formulação das suas ideias e possibilitando a análise do seu alcance e atualidade, sendo estruturada em três eixos temáticos: $1^{\circ}$ eixo temático: Contexto e influência da Pedagogia Paulo Freire; 2o eixo temático: Pedagogia Paulo Freire: categorias; $3^{\circ}$ eixo temático: Atualidade do pensamento freireano e intervenção pedagógica (GUEDES; SANTIAGO, 2017).

\footnotetext{
${ }^{1}$ Resenha crítica elaborada por Polliane Santos de Sousa, doutoranda do Programa de PósGraduação em Educação Científica e Tecnológica da Universidade Federal de Santa Catarina, na disciplina Estágio de Docência I desenvolvida no contexto da disciplina Pedagogia Paulo Freire.

${ }^{2}$ Ao longo do texto especifica-se o vínculo da Cátedra Paulo Freire com a Universidade Federal de Pernambuco por se tratar de uma dentre as Cátedras Paulo Freire existentes no país. $O$ reconhecimento da obra de Paulo Freire mediante a criação de Cátedras para o desenvolvimento de ações de ensino, pesquisa e extensão tem sido realizado por mais de uma universidade no país, contribuindo com a preservação e aprofundamento do legado de Paulo Freire e sinalizando para a sua atualidade.
} 
Com uma bibliografia cuidadosamente selecionada, o desenvolvimento dos eixos temáticos ocorre mediante o estudo da própria obra de Paulo Freire. Dessa forma, crítica do uso frequente de excertos de livros de Paulo Freire descolados do seu contexto de elaboração e intencionalidade, a coordenação da disciplina oportuniza aos discentes um encontro valioso com a obra do autor, através da leitura de texto em sua inteireza.

Ancorada no rigor teórico-metodológico do contexto acadêmico, a disciplina também favorece um processo recursivo de aprendizagem que não se esgota na apreensão das categorias freireanas, mas no desenvolvimento de um processo sistemático de estudo, no qual estudantes e professores se constituem sujeitos. Tal aspecto é evidenciado nas primeiras aulas com a leitura do texto "Considerações em torno do ato de estudar" (FREIRE, 1981), que sintetiza a postura a ser vivenciada pelos indivíduos no processo de apreensão da Pedagogia Paulo Freire. Nesse sentido, o ato de estudar não ocorre passivamente, mas envolve perceber o condicionamento históricosociológico do conhecimento e do autor, desenvolver uma visão global da obra e também retomá-la para delimitar as suas dimensões parciais, assim como adotar uma postura curiosa, indagadora sobre o seu conteúdo (FREIRE, 1981).

Ainda no que concerne ao texto "Considerações em torno do ato de estudar" (FREIRE, 1981), é possível inferir que este constitui mais do que um guia para o estudo que se pretende desenvolver da obra de Paulo Freire, sendo explorado também no delineamento do plano de ensino da disciplina. Por exemplo, no referido texto, Paulo Freire adverte de antemão:

Uma relação bibliográfica não pode ser uma simples cópia de títulos, feita ao acaso, ou por ouvir dizer. Quem a sugere deve saber o que está sugerindo e por que o faz. Quem a recebe, por sua vez, deve ter nela, não uma prescrição dogmática de leituras, mas um desafio. (FREIRE, 1981, p. 8).

Essa intencionalidade para a seleção da bibliografia, apresentada pelo autor, torna-se evidente no decorrer da disciplina em função do recorte da vasta obra de Paulo Freire realizado pelas docentes ${ }^{3}$, que reflete períodos marcantes vivenciados por ele e contempla os diferentes formatos dos seus livros.

Nesse contexto, o desenvolvimento da disciplina é centrado na abordagem dos seguintes livros escritos por Paulo Freire:

\footnotetext{
${ }^{3}$ Destaca-se que o desenvolvimento da disciplina é realizado em docência compartilhada, uma vez que a disciplina é coordenada pelas professoras Dra. Maria Eliete Santiago e Dra. Marília Gabriela de Menezes Guedes.
} 
i) Educação e Atualidade Brasileira (FREIRE, 2003a), tese de concurso escrita por Paulo Freire em 1959 para concorrer à cadeira de História e Filosofia da Educação na Escola de Belas Artes de Pernambuco;

ii) Pedagogia do Oprimido (FREIRE, 2014), livro concluído em 1968 durante o exílio e considerado a principal obra do autor, iniciando uma elaboração teórica mais aprofundada, consistente e rigorosa da perspectiva freireana de educação;

iii) A educação na cidade (FREIRE, 2006), livro publicado em 1991, após o retorno de Paulo Freire do exílio ao Brasil, constituindo um relato introdutório das atividades desenvolvidas pela Secretaria Municipal de Educação de São Paulo durante a sua gestão;

iv) Política e educação (FREIRE, 2007), livro publicado em 1993, no qual Paulo Freire amplia os temas abordados em seus escritos, provocando nos leitores o desenvolvimento de uma compreensão crítica sobre a história e a educação;

v) Pedagogia da Autonomia: saberes necessários à prática educativa (FREIRE, 2003b), livro publicado em 1996, sendo a última obra publicada em vida, na qual Paulo Freire realiza uma análise das questões que a educação escolar frequentemente coloca aos educandos e estabelece uma valiosa ponte com a prática educativa dos educadores.

Vale salientar que o processo de estudo das obras se intensifica no decorrer da disciplina, uma vez que os discentes vão desenvolvendo mecanismos de análise e aprofundando as leituras. Assim, por exemplo, nas primeiras aulas, inicia-se um movimento de compreensão do contexto das obras, com alguma ênfase nas especificidades do pensamento freireano, enquanto nas últimas aulas intensifica-se o processo de cisão dos textos com o mapeamento de categorias fundantes do pensamento freireano, vislumbrando, em um processo dialético, a construção de sínteses pelos estudantes. Cabe destacar, portanto, a contribuição da opção teórico-metodológica da disciplina para a formação acadêmica dos diversos profissionais ali presentes. Afinal, cursavam a disciplina estudantes de diferentes áreas do conhecimento (Psicologia, Enfermagem, Pedagogia, Ciências Biológicas, Física, Química, Terapia Ocupacional, etc.), sinalizando para a abrangência da obra de Paulo Freire, que mais do que um "método" de alfabetização, constitui uma teoria do conhecimento e filosofia da educação (GADOTTI, 2004).

Ademais, precedente ao estudo das obras, realiza-se o reconhecimento do contexto de sua elaboração, da sua dimensão socio-histórica. Assim, o planejamento da disciplina é permeado pela exposição de especialistas, documentários e entrevistas vídeo gravadas com Paulo Freire, fornecendo subsídios para uma compreensão mais ampla do contexto de formulação da Pedagogia Paulo Freire. Destaca-se que, em função do ambiente colaborativo 
para a construção do conhecimento em sala de aula, com frequência tais exposições foram enriquecidas com contribuições dos estudantes, sejam elas solicitadas ao longo do processo ou apresentadas espontaneamente pelos discentes.

No que tange à abordagem de categorias da Pedagogia Paulo Freire, são discutidas aquelas consideradas fundantes para uma primeira aproximação com o pensamento freireano, evidenciando que as mesmas não estão localizadas em livros específicos, mas permeiam toda a obra do autor. Sem a pretensão de esgotar os aspectos discutidos, podem-se destacar as seguintes categorias selecionadas para análise na disciplina Pedagogia Paulo Freire:

i) Concepção de sujeito. $\mathrm{Na}$ abordagem desta categoria discute-se a compreensão ontológica de ser humano apresentada por Paulo Freire. Para o autor, os seres humanos constituem seres histórico-culturais, que ao terem consciência de si e do mundo podem se distanciar da realidade e objetivá-la, vivendo uma relação de enfrentamento com a mesma tendo em vista a superação das barreiras socialmente construídas que obstaculizam o ser mais ${ }^{4}$ (FREIRE, 2014).

ii) Educação. Nesta categoria várias dimensões da concepção de educação de Paulo Freire são discutidas, tal como a sua argumentação sobre a impossibilidade de a educação ser neutra. Em especial, na Pedagogia Paulo Freire o quefazer educativo é concebido como um ato de conhecimento, em que educandos e educadores exercem o papel de sujeitos cognoscentes e no qual o conhecimento científico constitui instrumento para o desvelamento da realidade e para a intervenção social (FREIRE, 1981, 1983).

iii) Dialogicidade e Problematização. A partir da discussão destas categorias, intrinsecamente relacionadas, explicita-se que em uma perspectiva educacional libertadora o diálogo se faz por meio da palavra que é proferida criticamente com vistas à transformação da realidade, sendo orientado pela problematização das relações homens-mundo. Para Freire (1983) é na aprendizagem mediada pelo mundo que se dá o "(re)ad-mirar" da realidade concreta para o reconhecimento da sua razão de ser. Ao problematizar a realidade propõe-se o distanciamento do educando da situação concreta para que, analisando-a criticamente, possa ser alcançada a compreensão da sua estrutura profunda (FREIRE, 1981).

O processo de construção de sínteses pelos discentes sobre as categorias foi orientado por um mapeamento temático, no qual os próprios estudantes identificavam excertos das obras que caracterizavam as categorias, proporcionando tanto oportunidades de análises textuais quanto de diálogo em sala de aula. Assim, as compreensões dos estudantes sobre as categorias

\footnotetext{
${ }^{4}$ A expressão ser mais diz respeito ao processo de busca permanente do ser humano enquanto seres inacabados, relevando outro elemento da concepção ontológica de Paulo Freire sobre o ser humano.
} 
estudadas não foram apresentadas como algo pronto e acabado, mas foram construídas coletivamente e ancoradas na obra de Paulo Freire.

Destaca-se que contribuir com o desenvolvimento da leitura crítica e autonomia dos estudantes no processo educativo também envolveu alguns desafios. Entre eles, pode-se mencionar como o mais marcante a dificuldade manifestada pelos estudantes para o desenvolvimento de um processo de leitura e escrita sistemático. Esta dificuldade, bastante familiar às coordenadoras da disciplina, foi amenizada com o desenvolvimento de um processo de escrita e reescrita. Para isso, os primeiros escritos, marcados por um ensino memorístico, eram problematizados iniciando um movimento voltado para a compreensão crítica e situada socio-historicamente da obra do autor e para a construção de compreensões autênticas por parte dos estudantes.

Ao final da disciplina, os estudantes expressaram também um maior interesse em conhecer experiências da Pedagogia Paulo Freire para o contexto escolar, aspecto não priorizado pela disciplina, por constituir ponto de partida para o estudo da obra de Paulo Freire e por possuir a limitação temporal dos calendários acadêmicos. Nesse contexto, vale sinalizar para a necessidade de ampliar o compartilhamento sistemático de pesquisas e experiências voltadas para a Educação Básica e Ensino Superior pautadas na Pedagogia Paulo Freire, proporcionando tanto uma melhor articulação entre os seus estudiosos quanto maior divulgação dos trabalhos desenvolvidos. Por outro lado, também vale destacar as iniciativas da Cátedra Paulo Freire/UFPE nesse sentido, com o desenvolvimento, por exemplo, do VII Seminário Paulo Freire | V Encontro de Cátedras e Grupos de Estudos.

Em síntese, a partir da experiência vivenciada, compreende-se que a disciplina Pedagogia Paulo Freire proporciona um encontro fidedigno e coerente com a concepção de educação de Paulo Freire. Constitui uma primeira aproximação com a obra do autor e vislumbra mais do que o reconhecimento das suas principais características, o desenvolvimento de uma compreensão crítica por parte dos discentes da sua obra, considerando o seu contexto de formulação e referências e instituindo um verdadeiro processo de estudo da mesma.

Convém enfatizar que diante de manifestações cada vez mais recorrentes que atacam o legado de Paulo Freire, condenam suas ideias e o responsabiliza pelas mazelas da educação, oportunidades para aproximações sistemáticas e estruturadas, tal como a proporcionada pela disciplina Pedagogia Paulo Freire, são fundamentais e extremamente recomendadas, seja para adotar os princípios educacionais de Paulo Freire ou para ao menos discordar, sem deturpações, tecendo argumentos verdadeiros e coerentes. 


\section{Referências}

CÁTEDRA PAULO FREIRE/UFPE. Apresentação. 2017.

Disponível em: <http://www.catedrapaulofreireufpe.org/sobre-acatedra/apresentacao/>. Acesso em: 28 jun. 2017.

FREIRE, P. Ação cultural para liberdade. 5. ed. Rio de Janeiro: Paz e Terra, 1981.

FREIRE, P. Extensão ou Comunicação? $8^{a}$ ed. Rio de Janeiro: Paz e Terra, 1983.

FREIRE, P. Educação e atualidade brasileira. $3^{a}$ ed. São Paulo: Cortez; Instituto Paulo Freire, 2003a.

FREIRE, P. Pedagogia da Autonomia: saberes necessários à prática educativa. $28^{\mathrm{a}}$ ed. São Paulo: Paz e Terra, 2003b.

FREIRE, P. A Educação na Cidade. $7^{\mathrm{a}}$ ed. São Paulo: Cortez, 2006.

FREIRE, P. Política e educação. $8^{a}$ ed. São Paulo: Villa das Letras, 2007.

FREIRE, P. Pedagogia do Oprimido. 58. ed. Rio de Janeiro: Paz e Terra, 2014.

GADOTTI, M. Convite à leitura de Paulo Freire. 2. ed. São Paulo-SP: Editora Scipione, 2004.

GUEDES, M. G.; SANTIAGO, E. Sobre a disciplina Pedagogia Paulo Freire: programação. Recife-PE: Cátedra Paulo Freire/UFPE, 2017.

MARCONI, M. De A.; LAKATOS, E. M. Fundamentos de metodologia científica. 5. ed. ed. São Paulo: Atlas, 2003.

TORRES, C. A. et al. Prefácio. Educação e atualidade brasileira. $3^{a}$ ed. São Paulo: Cortez; Instituto Paulo Freire, 2003, p. IX-XII. 